\title{
A Biased, Misleading Review on Early Angiosperms
}

\author{
Xin Wang \\ CAS Key Laboratory of Economic Stratigraphy and Palaeogeography, Nanjing Institute of Geology and \\ Palaeontology, Nanjing, China
}

Correspondence to: Xin Wang, Xinwang@nigpas.ac.cn

Keywords: Age, Angiosperms, Flowers, Review, Fossil, Origin, Jurassic

Received: September 18, 2017 Accepted: December 3, $2017 \quad$ Published: December 6, 2017

Copyright () 2017 by authors and Scientific Research Publishing Inc.

This work is licensed under the Creative Commons Attribution International License (CC BY 4.0).

http://creativecommons.org/licenses/by/4.0/

(c) (i) Open Access

\section{ABSTRACT}

A recently published review by Herendeen et al. is misleading, self-centered, self-praising, and self-conflicting. They excluded the famous early angiosperm Archaefructus from their list of exemplar angiosperms, which contained only fossil plants they published themselves, leaving the impression that they were only authoritative on the origin and early history of angiosperms. Their 57-year-old "No Angiosperms Until the Cretaceous" conception does not reflect the truth about the origin and early history of angiosperms. Reinforcing such vapidly repeated statement does not help resolving any problem in science but leads to no solution for the origin of angiosperms. The authors tried to establish a criterion identifying a fossil angiosperm but their own exemplar angiosperm Monetianthus overturns their own criterion. Apparently, such a review does not positively contribute much to science.

\section{INTRODUCTION}

The age of the angiosperms is a question of importance in botany because the answer to this question is hinged to the solution of many problems in various branches of botany. Palaeobotanists are the major group of scientists trying to answer this question. Unlike other botanists working on extant plants, palaeobotanists build their hypotheses mainly based on fossil evidence, not on reasoning, inferring, or imaginations.

\section{AN UNREALISITC VIEW OF THE HISTORY OF ANGIOSPERMS}

On March 3, 2017, Nature Plants published a review titled as "Palaeobotanical redux: revisiting the age of the angiosperms" authored by Herendeen et al. [1]. The review repeated a conclusion that was drawn 57 years before, namely, "No angiosperms until the Cretaceous". This statement on the history of angiosperms apparently does not reflect the progress made in palaeobotany and molecular systematics, both of which suggest pre-Cretaceous origin and history of angiosperms [2-22]. Herendeen et al. did not achieve a balanced view of the current fossil record of angiosperms, considering the following flaws inflicting 
the review.

\subsection{Herendeen et al. Refuted All Pre-Cretaceous Fossil Records without Showing Necessary Evidence}

In the review, they took effort to prove that Euanthus is closely comparable to Tsuga, without showing supporting evidence of key features. In the caption of their Figure 3, it seemed as if Herendeen et al. had established a correspondence between all parts of these two taxa, although they intentionally ignored the following facts. 1) The sepals and petals of Euanthus are distinct in size and morphology [3]: namely, the abaxial keel of the sepals is completely missing in the petals and, conversely, the transverse wrinkles on the petals is missing in the sepals of Euanthus (Figures 1(a)-(c)), while similar distinctionis lacking between the scales of Tsuga [1]. 2) The concentric wrinkles on the limb of the petals [3] (Figure 1(a)) are missing in all the scales of Tsuga [1]. 3) Several features, including hairy style, internal cavity (ovary) at the style bottom, and pentamerous receptacle, seen in Euanthus [3] have no counterparts in Tsuga [1]. 4) The tetrasporangiate anther of Euanthus (Figure 6(d) and Figure 6(h) of [3]) is frequently and only seen in angiosperms but never seen in gymnosperms (including Tsuga), even according to Herendeen et al. [1]. These nullify any close relationship between Euanthus and Tsuga (which belong to angiosperms and gymnosperms, respectively), and thus undermine the "No-Angiosperms-Until-Cretaceous" conception adopted by Herendeen et al.
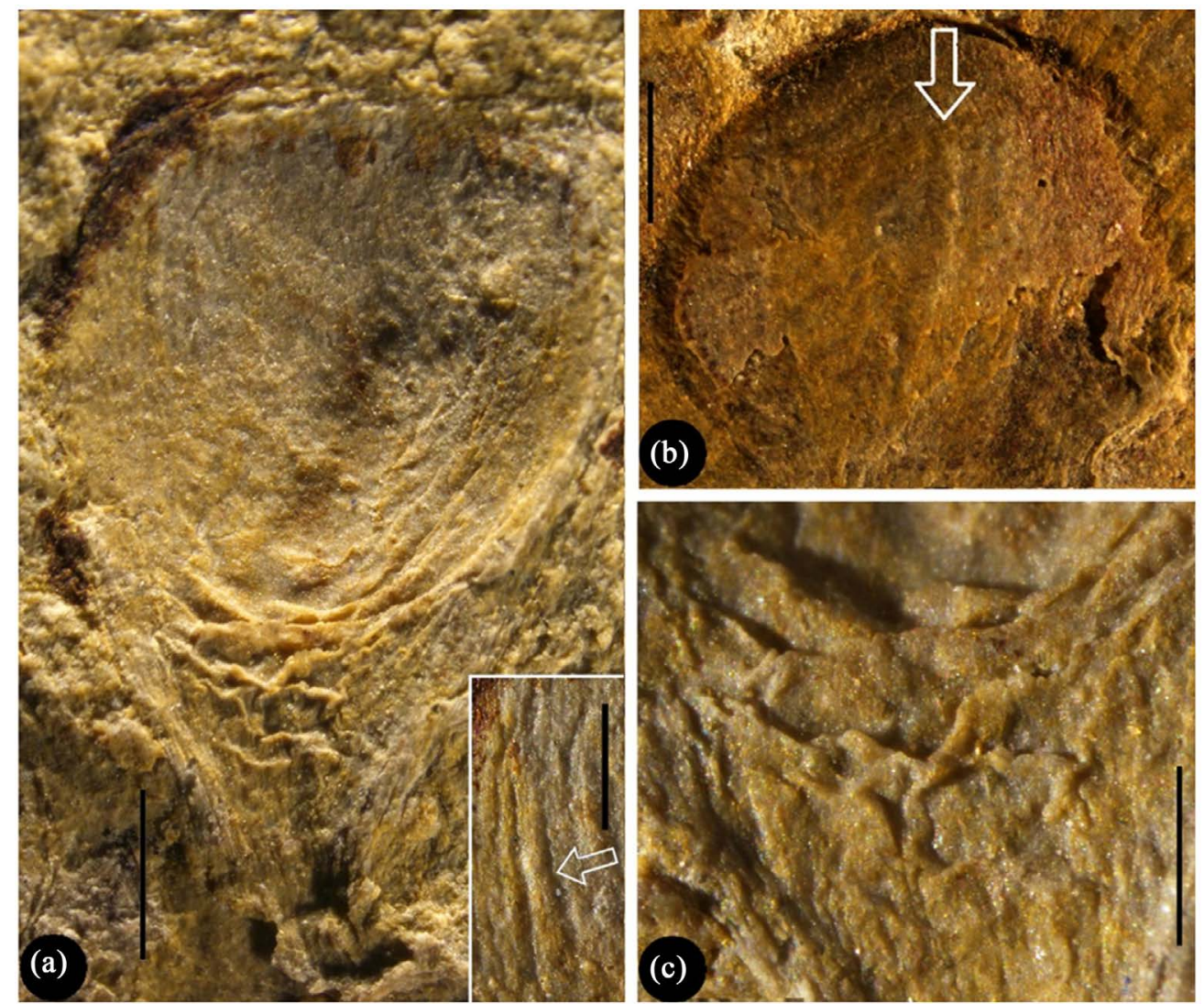

Figure 1. Sepal and petal of different mrophologies in Euanthus panii. Stereomicroscopy. Reproduced from Liu and Wang [3] with permission from Historical Biology. (a) Adaxial view of a petal, showing a round concave limb and a claw with transverse wrinkles. Bar $=1 \mathrm{~mm}$. The inset shows the concentric wrinkles along the limb margin. Inset bar $=0.5 \mathrm{~mm}$; (b) Abaxial keel (arrow) on a sepal. Bar $=1 \mathrm{~mm}$; (c) Transverse wrinkles on the distal of the claw shown in A. Bar $=0.5 \mathrm{~mm}$. 


\subsection{Herendeen et al. Made Groundless Claims about Solaranthus without Showing Required Evidence}

Herendeen et al. claimed that they found "resin bodies" and "pollen sacs" in Solaranthus but none of their figures supported such claims. Uncritically, they accepted the conclusion of Deng et al. [23], who showed neither pollen sacs nor origin of pollen grains. Deng et al. [23] thought that Wang and Zheng [16] had misinterpreted the "pollen sacs" (in Deng et al.'s sense) as "tepals". The funny thing is that the specimens Deng et al. studied had no "tepals", namely, no "pollen sacs" (in Deng et al.'s sense). Then two questions have to be answered before believing Deng et al.: 1) Did Deng et al. really study the plant called Solaranthus? 2) Without so-called "pollen sacs" (in Deng et al.'s sense), where came their in situ pollen grains? Herendeen et al. ignored the well-documented stamens with in situ monocolpate pollen grains in Solaranthus [22]. Their "resin body" interpretation apparently cannot account for the assumed ovule on the ovary bottom of Solaranthus shown in Figures 2(a)-(d). So the doubt over Solaranthus as an angiosperm both by Deng et al. and Herendeen et al. is groundless, making their conclusion tentative.
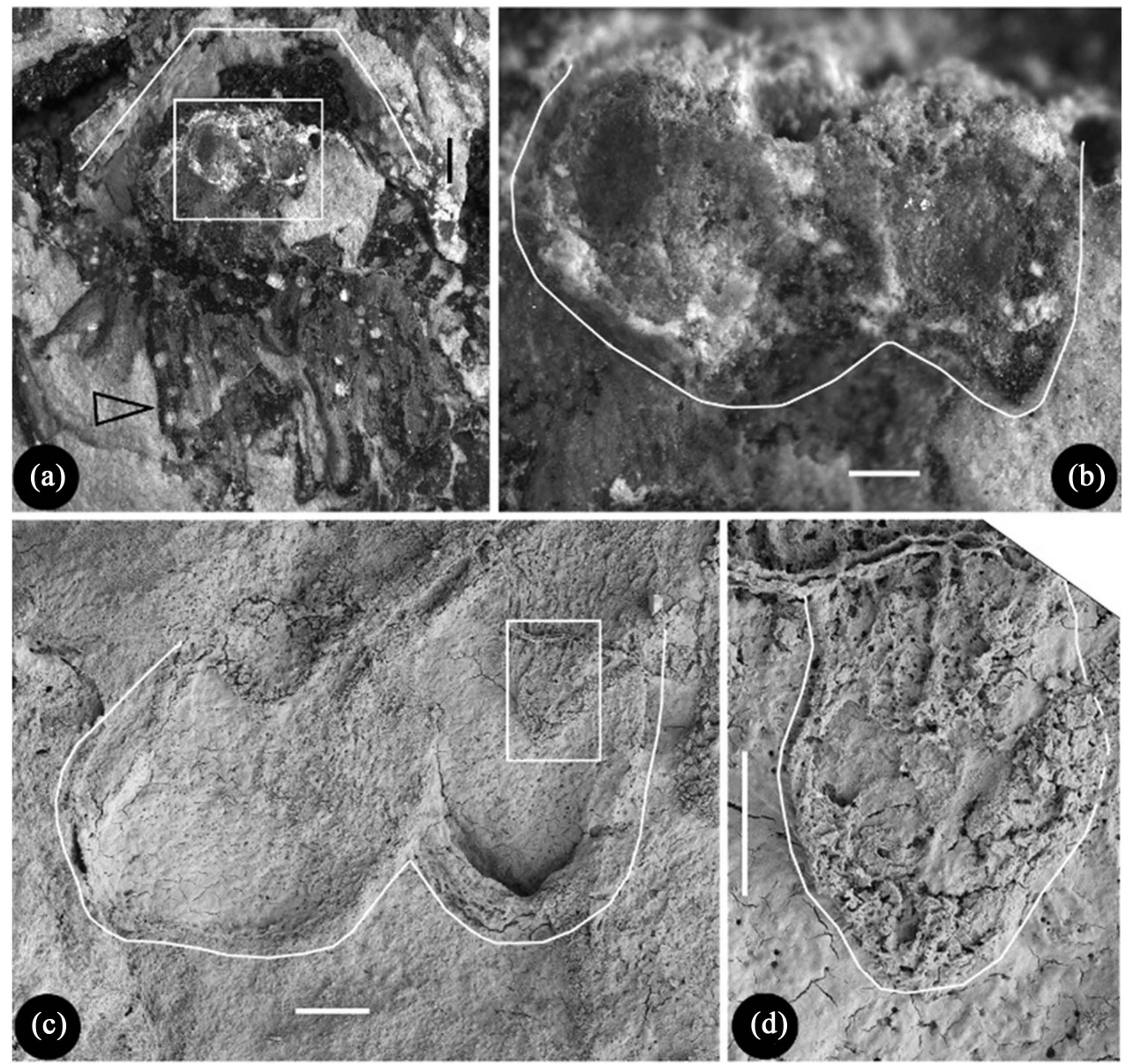

Figure 2. Carpel and ovule of Solaranthus daohugouensis. Reproduced from Zheng and Wang [22] with permission from Acta Geologica Sinica (English Edition). (a) A longitudinal view of a flower, showing the angular outline of the peltate head (white line) and tepals (arrow) on the bottom. Stereomicrography. Bar $=0.5 \mathrm{~mm}$; (b) A detailed view of the rectangle in A, showing the impressions (outlined by white line) left by two carpels on the sediments. Stereomicrography. Bar $=0.2 \mathrm{~mm}$; (c) The carpels in B showing their outline (white line). SEM. Bar $=0.2 \mathrm{~mm}$; (d) Detailed view of the rectangle in (c), showing the outlined ovule attached to the bottom of the ovary. SEM. Bar $=0.1 \mathrm{~mm}$. 


\subsection{Herendeen et al. Set up Bad Examples of Studying Fossil Angiosperms, Misleading Future Palaeobotanists}

Their list of "exemplar" early angiosperms is $100 \%$ of their own and even named after one of themselves! The motive of such listing is never released to the public, but it is obviously self-centered. Their first "exemplar" early angiosperm, Monetianthus, was initially asserted as the "oldest" fossil angiosperm, with a Nymphaealean affinity [24] (an affinity soon rejected [25]), but was later found much younger than initially claimed [26-28] and thus has little to do with "EARLY" angiosperms. The pre-existing much older famous Archaefructus [18] was fully and consistently ignored in both publications of Monetianthus [24, 28]. Friis et al. gave up the championship later [28], for unstated reason. Despite ONE integument shown clearly in Figure 5(f) of [28], Monetianthus was interpreted as having TWO integuments [28]. The $>10 \mu \mathrm{m}$ wide ventral slits on the top of the female part of Monetianthus (Figure 2(b) [28]) made its angiospermous affinity spurious, as gymnospermous pollination cannot be fully ruled out in Monetianthus. The arrangement of the perianth of Monetianthus was described "may be spiral" ([24], p. 358) AND "in apparent whorls" (Page 359 [24]) in the same paper, "most likely not spiral" later ([28], p. 1092), and finally "not completely clear" (Page 173) [29] by the SAME authors. At least four features required for Nymphaeaceae were missing in Monetianthus [24]. Considering the lacks of 1) bitegmic ovules, 2) full enclosure of ovules, 3 ) stamen (not mention tetrasporangiate one), 4) pollen grains with radially or globally arranged apertures [28], 5) antedated age, and 6) doubt over its Nymphaealean affinity [25], whether Monetianthus is an angiosperm (not mention Nymphaeaceae) is still an open question, even according to angiosperm criteria proposed by Herendeen et al. ([1], p. 3). Archaefructus has been well-documented by various authors several times [2] [17-19], and Sinocarpus has been documented by authors including Friis [20, 21]. Although both of them are much older than their so-called "exemplar" early angiosperms listed in the review [1], both Archaefructus and Sinocarpus were either suspected or ignored in the review. Such a treatment is misleading, dishonest, and apparently non-professional, especially in a paper focusing on "the age of angiosperms". If Herendeen et al. [1] excluded Archaefructus because of former controversy over its age and phylogenetic position, apparently Monetianthus is more troublesome in the same terms and more qualified to be ignored or excluded. If Archaefructus with "closed carpel" [18] and Sinocarpus "with unambiguous angiospermous features" [20] were not angiosperms, Herendeen et al. should have declared clearly and supported their declarations with evidence. Without required declarations and evidence, the listing of early angiosperms by Herendeen et al. [1] is at least incomplete, partial, misleading, and thus inacceptable.

\subsection{A Formidable Trend in Palaeobotany}

The most formidable trend in current palaeobotany is that an increasing number of authors in palaeobotany (including some of Herendeen et al.) are misinterpreting data according to their own academic needs. Besides the above assertion of two integuments in Monetianthus [28], similar assertions of ONE (instead of MORE) seed in so-called "Umkomasia" [30], TWO (instead of ONE) veins in Pseudotorellia [31, 32], and "FREE" (instead of FUSED) carpels in Kajanthus [33] by similar authors have formed a line of poor publications in palaeobotany. Such errors are obvious, especially when Figure 4(b) and Figure 4(c) of Shi et al. [30] are compared, which were supposed of the same thing but quite distinct in vision, especially in term of number of seeds. The asserted "free" carpels in Kajanthus are actually totally fused from the bottom to the apex [33]. It is noteworthy that such a misinterpretation is NEEDED and FAVORS the relationship between Kajanthus and Sinofranchetia [33], which has free carpels [34, 35], which was preferred by Mendes et al. Reticence on gynoecium and carpels, standing in a marked contrast against the elaborated discussion on sexuality, merism, perianth, androecium, and pollen, of Kajanthus [33] per se partially reflects Mendes et al.'s diffidence on their asserted "free" carpels. How can such obvious errors be made and escape the attention of the reviewers? This is a question deserving attention of everyone.

\subsection{Herendeen et al. Failed to Remain Consistent within Their Short Review}

Although angio-ovuly is the only consistent difference that separates angiosperms from gymnosperms $[11,18,36]$, Herendeen et al. [1] added three more features to the criterion and, incredibly, they failed to 
obey their OWN rule themselves because the first "exemplar" early angiosperm Monetianthus does satisfy their own criterion! Herendeen et al. [1] rejected Juraherba bodae as an angiosperm based on an excuse: "the leaf is too thin" (a feature not among the criterion they proposed). Such a whimsical treatments is unprecedented in botany!

\subsection{Herendeen et al. Were Over-Brief in Their Rejecting Jurassic Macrofossil Angiosperms}

Without showing any evidence, they spent just 1 sentence to nullify Yuhania documented by a paper of 11 pages, 0.5 sentence on Xingxueanthus of 9 pages, and 1.5 sentences on Schmeissneria of 23 pages. These pre-Cretaceous angiosperms were recognized on the basis of presence of enclosed ovules, a feature proposed and applied by various authors $[11,18,36]$. Such a parsimony in wording has little to with authority of Herendeen et al. but reflects their diffidence in their treatments.

\subsection{Herendeen et al. Misinterpreted the Original Meaning of Others}

Herendeen et al. gave misleading impressions as if some of early angiosperms had been rejected by a third party despite the fact is not so. The paper Herendeen et al. cited to nullify the angiosperm affinity of Schmeissneria [37] actually had little to do with true Schmeissneria, as fully refuted before (Page 716-717) [3]. The way Herendeen et al. treated Liaoningfructus implied that Wong et al. [38] had transferred Liaoningfructus into Archaeamphora/Liaoningocladus. But the fact is that Wong et al. [38] have never even mentioned Liaoningfructus at all throughout their publication. In all these cases, although Herendeen et al. did not release their own true motive, the consequence is obvious: the readers were misled.

\section{CONCLUSION}

The above mistreatments of information heavily undermine the "No-Angiosperms-Until-Cretaceous" conclusion, which was re-claimed by Herendeen et al. [1]. It is risky and takes a great courage for a scientist to endorse and repeat an old conclusion that was based on data available decades before. Doing so is detrimental to palaeobotany, which is a vivid, not fossilized, science.

\section{ACKNOWLEDGEMENTS}

This research was supported by the National Natural Science Foundation of China (41688103, 91514302, 91114201, 41572046), Strategic Priority Research Program (B) of Chinese Academy of Sciences (Grant No. XDPB05, XDB18000000). This is a contribution to UNESCO IGCP632.

\section{REFERENCES}

1. Herendeen, P.S., Friis, E.M., Pedersen, K.R. and Crane, P.R. (2017) Palaeobotanical Redux: Revisiting the Age of the Angiosperms. Nature Plants, 3, 17015. https://doi.org/10.1038/nplants.2017.15

2. Ji, Q., Li, H., Bowe, M., Liu, Y. and Taylor, D.W. (2004) Early Cretaceous Archaefructus eoflora sp. nov. with Bisexual Flowers from Beipiao, Western Liaoning, China. Acta Geologica Sinica (English Edition), 78, 883-896.

3. Liu, Z.-J. and Wang, X. (2016) A Perfect Flower from the Jurassic of China. Historical Biology, 28, 707-719. https://doi.org/10.1080/08912963.2015.1020423

4. Liu, Z.-J. and Wang, X. (2017) Yuhania: A Unique Angiosperm from the Middle Jurassic of Inner Mongolia, China. Historical Biology, 29, 431-441. https://doi.org/10.1080/08912963.2016.1178740

5. Han, G., Fu, X., Liu, Z.-J. and Wang, X. (2013) A New Angiosperm Genus from the Lower Cretaceous Yixian Formation, Western Liaoning, China. Acta Geologica Sinica (English Edition), 87, 916-925. https://doi.org/10.1111/1755-6724.12100

6. Han, G., Liu, Z. and Wang, X. (2017) A Dichocarpum-Like Angiosperm from the Early Cretaceous of China. Acta Geologica Sinica (English Edition), 90, 1-8. https://doi.org/10.1111/1755-6724.13059 
7. Han, G., et al. (2016) A Whole Plant Herbaceous Angiosperm from the Middle Jurassic of China. Acta Geologica Sinica (English Edition), 90, 19-29. https://doi.org/10.1111/1755-6724.12592

8. Hochuli, P.A. and Feist-Burkhardt, S. (2004) A Boreal Early Cradle of Angiosperms? Angiosperm-Like Pollen from the Middle Triassic of the Barents Sea (Norway). Journal of Micropalaeontology, 23, 97-104. https://doi.org/10.1144/jm.23.2.97

9. Hochuli, P.A. and Feist-Burkhardt, S. (2013) Angiosperm-Like Pollen and Afropollis from the Middle Triassic (Anisian) of the Germanic Basin (Northern Switzerland). Frontiers in Plant Science, 4, 344. https://doi.org/10.3389/fpls.2013.00344

10. Prasad, V., et al. (2011) Late Cretaceous Origin of the Rice Tribe Provides Evidence for Early Diversification in Poaceae. Nature Communication, 2, 480. https://doi.org/10.1038/ncomms1482

11. Wang, X. (2010) The Dawn Angiosperms. Springer, Heidelberg. https://doi.org/10.1007/978-3-642-01161-0

12. Wang, X. (2010) Schmeissneria: An Angiosperm from the Early Jurassic. Journal of Systematics and Evolution, 48, 326-335. https://doi.org/10.1111/j.1759-6831.2010.00090.x

13. Wang, X., Duan, S., Geng, B., Cui, J. and Yang, Y. (2007) Schmeissneria: A Missing Link to Angiosperms? BMC Evolutionary Biology, 7, 14. https://doi.org/10.1186/1471-2148-7-14

14. Wang, X. and Han, G. (2011) The Earliest Ascidiate Carpel and Its Implications for Angiosperm Evolution. Acta Geologica Sinica (English Edition), 85, 998-1002. https://doi.org/10.1111/j.1755-6724.2011.00534.x

15. Wang, X., et al. (2015) Breaking the Stasis of Current Plant Systematics. Science and Technology Review, 33, 97-105.

16. Wang, X. and Zheng, S. (2009) The Earliest Normal Flower from Liaoning Province, China. Journal of Integrative Plant Biology, 51, 800-811. https://doi.org/10.1111/j.1744-7909.2009.00838.x

17. Wang, X. and Zheng, X.-T. (2012) Reconsiderations on Two Characters of Early Angiosperm Archaefructus. Palaeoworld, 21, 193-201.

18. Sun, G., Dilcher, D.L., Zheng, S. and Zhou, Z. (1998) In Search of the First Flower: A Jurassic Angiosperm, Archaefructus, from Northeast China. Science, 282, 1692-1695. https://doi.org/10.1126/science.282.5394.1692

19. Sun, G., et al. (2002) Archaefructaceae, a New Basal Angiosperm Family. Science, 296, 899-904. https://doi.org/10.1126/science.1069439

20. Leng, Q. and Friis, E.M. (2003) Sinocarpus decussatus gen. et sp. nov., a New Angiosperm with Basally Syncarpous Fruits from the Yixian Formation of Northeast China. Plant Systematics and Evolution, 241, 77-88. https://doi.org/10.1007/s00606-003-0028-8

21. Leng, Q. and Friis, E.M. (2006) Angiosperm Leaves Associated with Sinocarpus Infructescences from the Yixian Formation (Mid-Early Cretaceous) of NE China. Plant Systematics and Evolution, 262, 173-187. https://doi.org/10.1007/s00606-006-0461-6

22. Zheng, S. and Wang, X. (2010) An Undercover Angiosperm from the Jurassic of China. Acta Geologica Sinica (English Edition), 84, 895-902. https://doi.org/10.1111/j.1755-6724.2010.00252.x

23. Deng, S., Hilton, J., Glasspool, I.J. and Dejax, J. (2014) Pollen Cones and Associated Leaves from the Lower Cretaceous of China and a Re-Evaluation of Mesozoic Male Cycad Cones. Journal of Systematic Palaeontology, 12, 1001-1023. https://doi.org/10.1080/14772019.2013.819817

24. Friis, E.M., Pedersen, K.R. and Crane, P.R. (2001) Fossil Evidence of Water Lilies (Nymphaeales) in the Early Cretaceous. Nature, 410, 357-360. https://doi.org/10.1038/35066557

25. Gandolfo, M.A., Nixon, K.C. and Crepet, W.L. (2004) Cretaceous Flowers of Nymphaeaceae and Implications for Complex Insect Entrapment Pollination Mechanisms in Early Angiosperms. Proceeding of National Academy of Sciences, United States, 101, 8056-8060. https://doi.org/10.1073/pnas.0402473101 
26. Heimhofer, U., Hochuli, P.A., Burla, S., Dinis, J.M.L. and Weissert, H. (2005) Timing of Early Cretaceous Angiosperm Diversification and Possible Links to Major Paleoenvironmental Change. Geology, 33, 141-144. https://doi.org/10.1130/G21053.1

27. Heimhofer, U., Hochuli, P.A., Burla, S. and Weissert, H. (2007) New Records of Early Cretaceous Angiosperm Pollen from Portuguese Coastal Deposits: Implications for the Timing of the Early Angiosperm Radiation. Review of Palaeobotany and Palynology, 144, 39-76.

28. Friis, E.M., Pedersen, K.R., von Balthazar, M., Grimm, G.W. and Crane, P.R. (2009) Monetianthus mirus gen. et sp. nov., a Nymphaealean Flower from the Early Cretaceous of Portugal. International Journal of Plant Sciences, 170, 1086-1101. https://doi.org/10.1086/605120

29. Friis, E.M., Pedersen, K.R. and Crane, P.R. (2010) Diversity in Obscurity: Fossil Flowers and the Early History of Angiosperms. Philosophical Transactions of the Royal Society B: Biological Sciences, 365, 369-382. https://doi.org/10.1098/rstb.2009.0227

30. Shi, G., et al. (2016) Early Cretaceous Umkomasia from Mongolia: Implications for Homology of Corystosperm Cupules. New Phytologist, 210, 1418-1429. https://doi.org/10.1111/nph.13871

31. Shi, G., et al. (2017) Leaves of Podozamites and Pseudotorellia from the Early Cretaceous of Mongolia: Stomatal Patterns and Implications for Relationships. Journal of Systematic Palaeontology. https://doi.org/10.1080/14772019.2016.1274343

32. Herrera, F., et al. (2017) The Presumed Ginkgophyte Umaltolepis Has Seed-Bearing Structures Resembling Those of Peltaspermales and Umkomasiales. Proceedings of the National Academy of Sciences, 114, E2385-E2391. https://doi.org/10.1073/pnas.1621409114

33. Mendes, M.M., Grimm, G.W., Pais, J. and Friis, E.M. (2014) Fossil Kajanthus lusitanicus gen. et sp. nov. from Portugal: Floral Evidence for Early Cretaceous Lardizabalaceae (Ranunculales, Basal Eudicot). Grana, 53, 283-301. https://doi.org/10.1080/00173134.2014.932431

34. Zhang, X.-H., Ren, Y. and Tian, X.-H. (2009) Floral Morphogenesis in Sinofranchetia (Lardizabalaceae) and Its Systematic Significance. Botanical Journal of the Linnean Society, 160, 82-92. https://doi.org/10.1111/j.1095-8339.2009.00835.x

35. Zhang, X.-H., Ren, Y., Tian, X.-H. and Pan, L.-Z. (2005) Anatomical Studies on Sinofranchetiachinensis (Lardizabalaceae) and Their Systematic Significance. Botanical Journal of the Linnean Society, 149, 271-281. https://doi.org/10.1111/j.1095-8339.2005.00453.x

36. Tomlinson, P.B. and Takaso, T. (2002) Seed Cone Structure in Conifers in Relation to Development and Pollination: A Biological Approach. Canadian Journal of Botany, 80, 1250-1273. https://doi.org/10.1139/b02-112

37. Van Konijnenburg-van Cittert, J.H.A. (2010) The Early Jurassic Male Ginkgoalean Inflorescence Stachyopitys preslii Schenk and Its in Situ Pollen. Scripta Geologica, 7, 141-149.

38. Wong, W.O., Dilcher, D.L., Labandeira, C.C., Sun, G. and Fleischmann, A. (2015) Early Cretaceous Archaeamphora Is Not a Carnivorous Angiosperm. Frontiers in Plant Science, 6, 326.

https://doi.org/10.3389/fpls.2015.00326 